SUPPORTING INFORMATION

\title{
Interrogating the Quaternary Structure of Noncanonical Hemoglobin Complexes by Electrospray Mass Spectrometry and Collision-
}

\section{Induced Dissociation}

\author{
Alexander I. M. Sever, Victor Yin, and Lars Konermann* \\ Department of Chemistry, The University of Western Ontario, London, Ontario, N6A 5B7, Canada \\ * To whom correspondence should be addressed. E-mail: konerman@uwo.ca.
}

This file contains:

Figure S1: CID spectra of $\mathrm{Hb}$ complexes at $40 \mathrm{~V}$.

Figure S2: Hexamer CID data at different collision energies.

Figure S3: Full CID spectra of tetramers, hexamers, and octamers at different collision energies.

Figure S4: CID spectra of charge-reduced $\mathrm{Hb}$ tetramers. 
A CID of $19+$ Tetramer

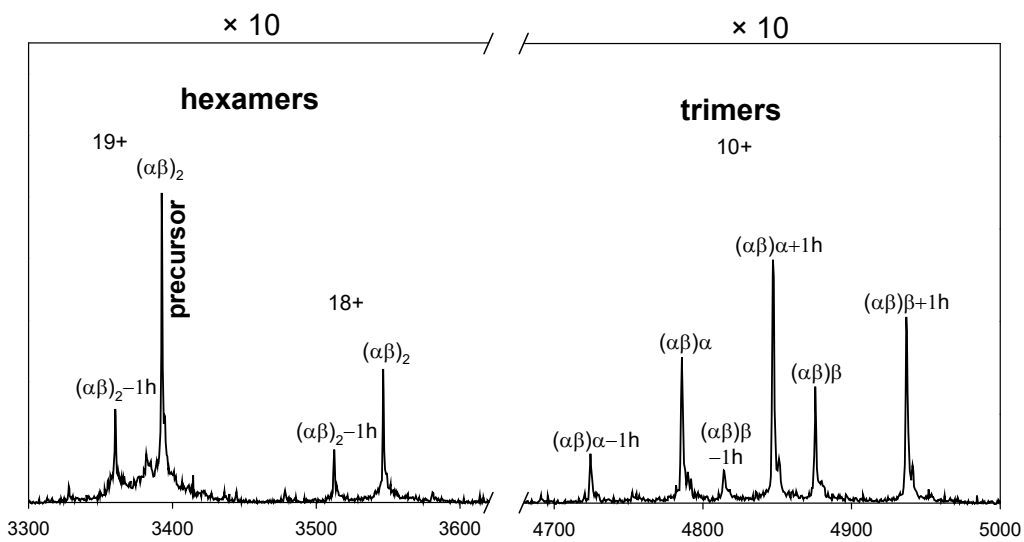

B CID of $23+$ Hexamer

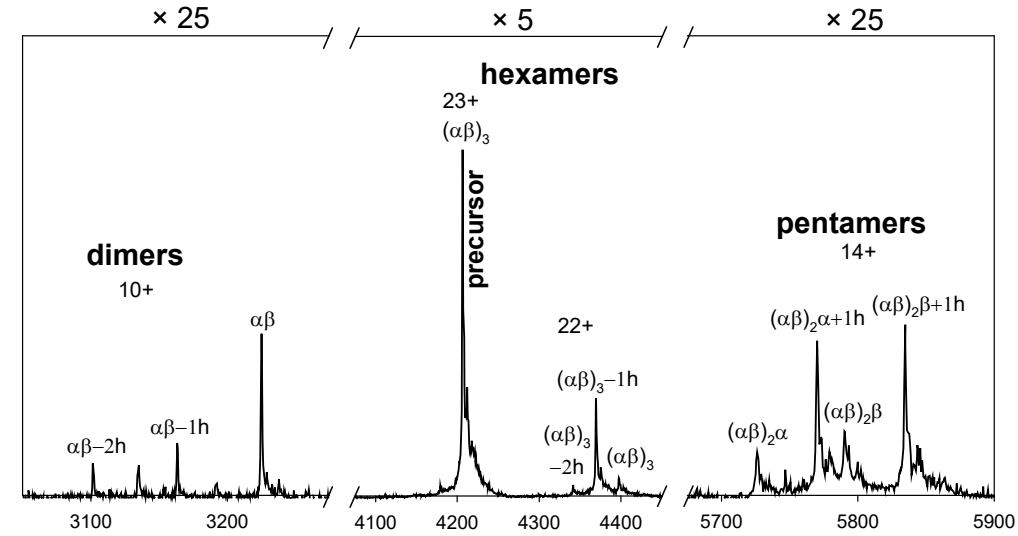

C CID of $27+$ Octamer

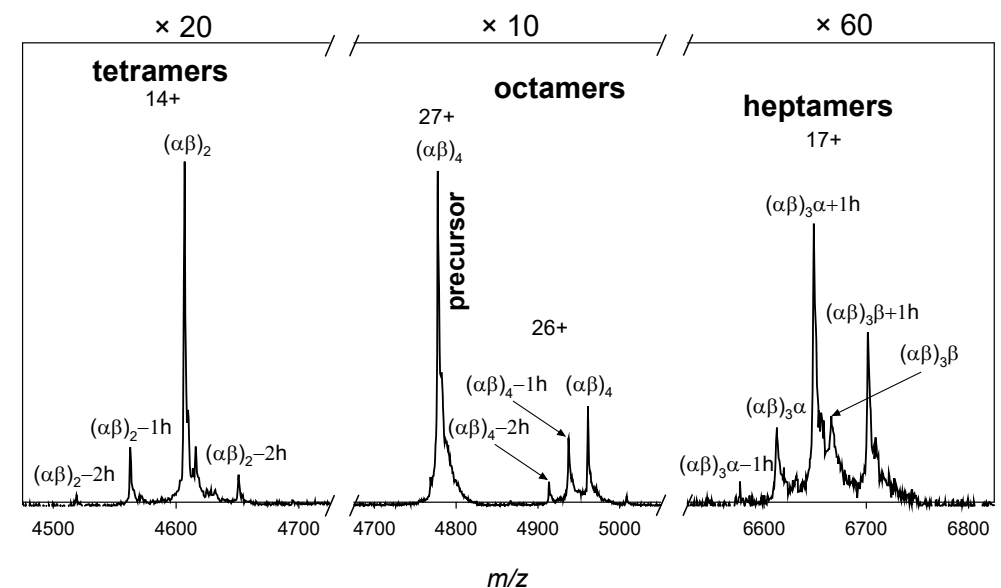

Figure S1. CID tandem mass spectra of different $\mathrm{Hb}$ complexes at a trap collision energy of $40 \mathrm{~V}$. These are the same data as in Figure 2, zoomed into specific regions to facilitate the annotation of fragment ions. $\alpha$ and $\beta$ refer to heme-containing subunits. The presence of an additional heme is indicated as $+1 \mathrm{~h}$, while the loss of one heme is denoted as $-1 \mathrm{~h}$. 


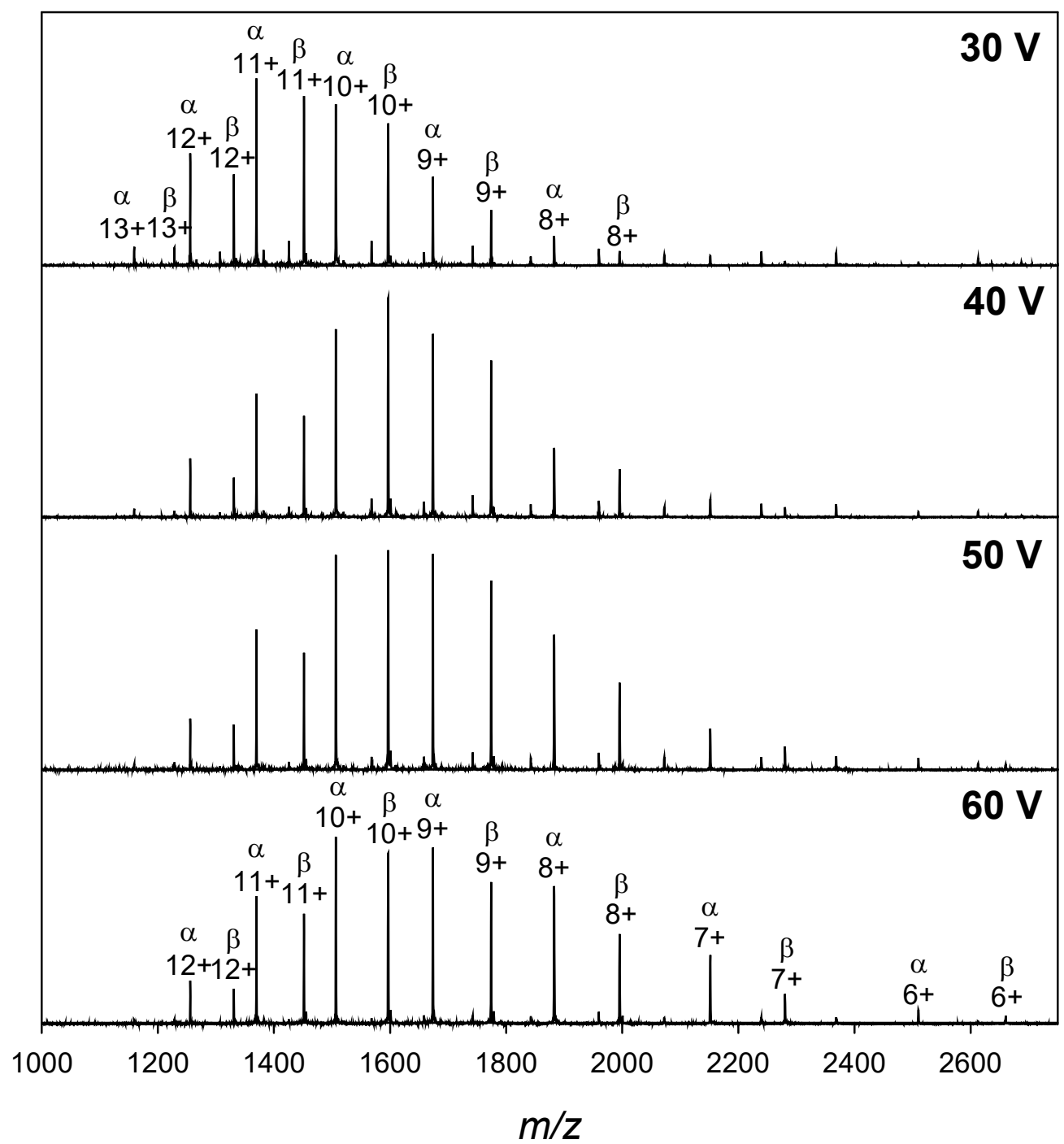

Figure S2. Partial CID tandem mass spectra, showing monomeric fragment ions obtained after CID of $23+$ hexamers. 
A CID of 19+ Tetramer

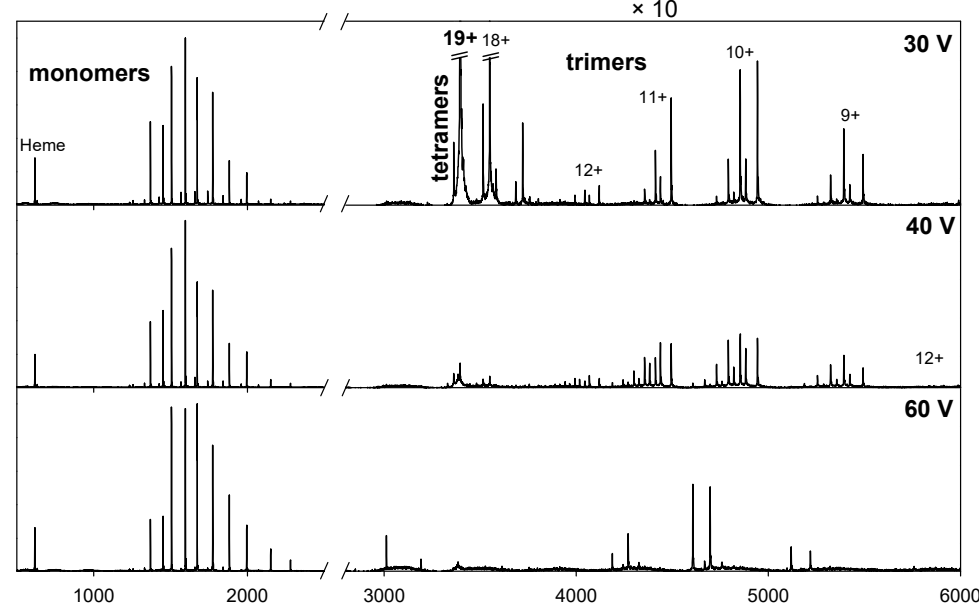

B CID of $23+$ Hexamer

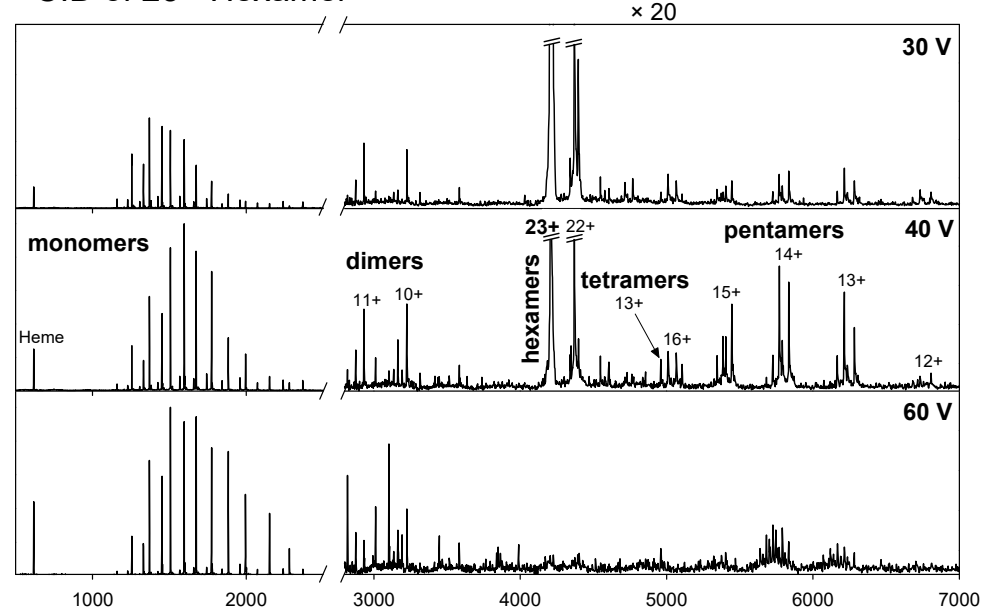

C CID of $27+$ Octamer

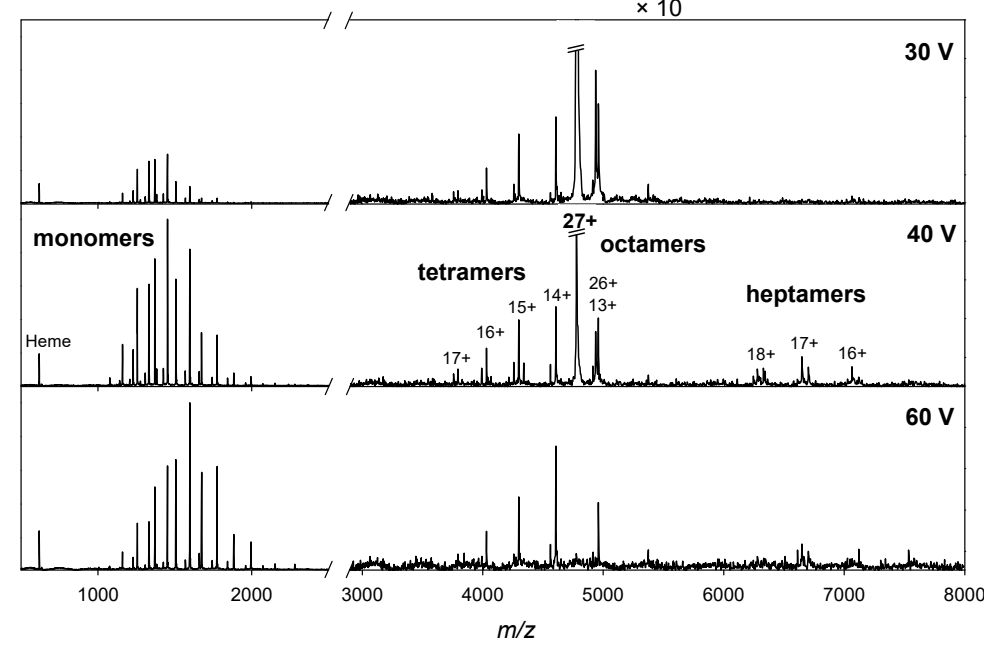

Figure S3. Tandem mass spectra obtained after CID of 19+ tetramers, 23+ hexamers, and 27+ octamers at different trap collision energies $(30 \mathrm{~V}, 40 \mathrm{~V}, 60 \mathrm{~V})$. These are the same data as in Figures 4 and S2, but as full spectra. 


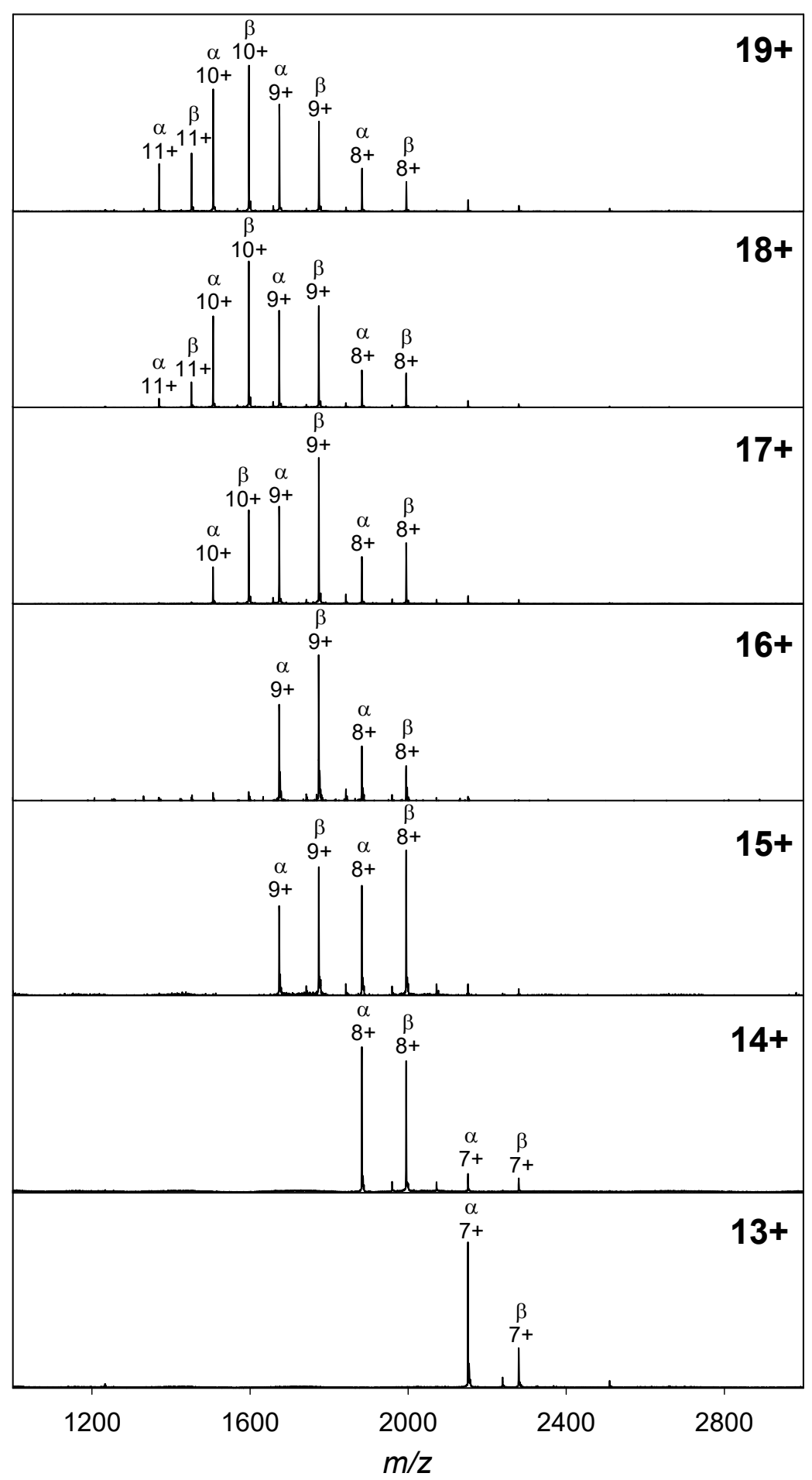

Figure S4. Tandem mass spectra obtained after CID of $(\alpha \beta)_{2}$ tetramers, in different charge states. Charge states $13+$ to $16+$ were produced after charge reduction using triethylammonium acetate, $2.5 \mathrm{mM}$ for $16+/ 15+$, and $10 \mathrm{mM}$ for $14+/ 13+$. Trap collision energies were between $70 \mathrm{~V}$ for $13+$, and $50 \mathrm{~V}$ for $19+$. 